\title{
CHALLENGING THE
}

\section{$\boldsymbol{H}$

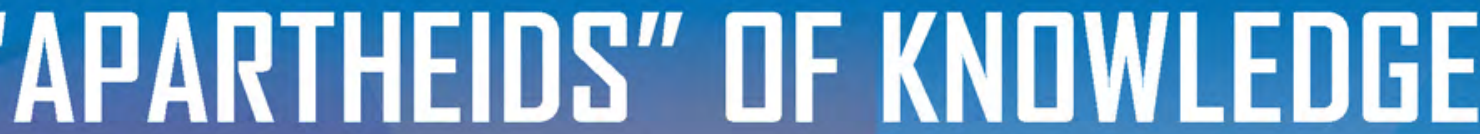
in Higher Education through Sacial Innavation

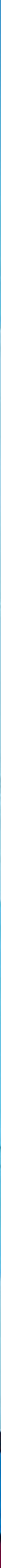




\section{Chapter 10}

\section{Telling stories about stories: Towards ethical guidelines for $\mathrm{HE}$ in digital storytelling \\ Daniela Gachago, Jacqui Scheepers and Candice Livingston}

CAPE PENINSULA UNIVERSITY OF TECHNOLOGY gachagod@gmail.com; scheepersj@cput.ac.za;

livingstonc@cput.ac.za

\section{Introduction}

Originating from community work, digital storytelling (DST) has been embraced in educational settings because of its potential to empower students through personal reflection, growth and the development of new literacies. The founding father of DST, Joe Lambert, states that this genre has made it "into every corner of higher education" (2017:vi). Digital storytelling has also carved a niche for itself as a qualitative research methodology (Haigh, 2017), mostly in health sciences/ health education (Haigh, 2017; Gubrium, Hill \& Flicker, 2014; Hill, 2014; Hardy, 2017). Increasingly other disciplines are adopting DST research methodologies as well, such as teacher education, where our own research resides (Condy, Chigona, Gachago \& Ivala, 2012; Gachago, Ivala, Condy \& Chigona, 2013; Gachago, 2015; Stewart \& Ivala, 2017; Thomson Long \& Hall, 2017; Livingston, 2014).

Digital storytelling is rooted in the rich history of oral narratives. Storytelling, a genre that transcends all disciplines, can be used to engage participants from all walks of life and often relies on a personal history story that is shared orally. The universalising nature of storytelling allows for the understanding of many different contexts (Van Luyn, 2011). Jessee (2011) notes that oral storytelling has 
the potential to humanise history and that the narratives of ordinary people have generally been absent from the tomes of history. The StoryCenter ${ }^{1}$ (former Center for Digital Story) set out do exactly that: to help make stories that are usually not heard accessible to a wider audience. Introducing DST at our institution has improved digital literacies and student engagement, provided a space for critical reflection and enhanced multicultural learning and an engagement across difference.

Through digital media and a carefully facilitated storytelling and production process, the telling of these unheard stories empower ordinary people to share what is important to them (Lambert, 2013). Their focus on usually unheard/unshared stories means that many of these stories have sensitive content that can render the storyteller vulnerable. Although literature agrees that the positive aspects of collecting these previously marginalised/misrepresented (digital) stories can only be of benefit to the greater population, there are inherent ethical dangers in collecting these stories, especially if they depict trauma. Adopting this emotional and process-orientated practice into an educational context, with its constraints of course objectives, assessment regimes, timetables and large classes, raises ethical concerns. What support and follow-up mechanisms exist to help students cope with an emotional fallout? Is it ethical to assign marks to these stories? How well equipped are educators to handle strong emotions and difficult dialogues in the classroom? How would one go about writing about the digital stories collected? How would it be possible to follow the rigid ethical guidelines as stipulated in "research with sentient beings" (Mandal, Acharya \& Parija, 2011:n.p.) in a process that is designed to elicit discomfort? How is it possible to adhere to the stringent rules regarding the anonymisation of data in a practice that is inherently transparent?

This chapter addresses these questions under a broader discussion of our experiences working with DST within the three different prongs of HE. Building on previous work done at our institution (Livingston, 2014; Gachago, 2015; Gachago \& Sykes, 2017; Stewart \& Ivala, 2017), we will reflect on our own DST practices in teaching and learning, research and community engagement. Through our own stories of ethical dilemmas we have encountered in our practice, we will show the complexities academics, researchers and practitioners adopting DST will have to face and negotiate in teaching and learning, research and community engagement. We write to invite practitioners to consider DST and the ethical dilemmas confronted in its practice, hoping that this chapter will initiate a wider discussion on their ethics of practice. As such, it, like much of this volume, considers, but

1 www.storycentre.org 
does not necessarily conclusively provide, answers to the questions it raises. Answers, in such early phases of exploration into a field, must come from the discussions it stimulates.

There is a growing interest in these issues, and the urgency to move towards an ethical practice of DST in HE is felt. Some of us were also part of the 2017 Untold $^{2}$ conference, which featured a stream on ethics across various DST contexts, including HE, and influenced much of our thinking in this chapter. Although the StoryCenter and their close collaborators such as Silence Speaks ${ }^{3}$, PatientVoices ${ }^{4}$ or The Silver Stories Partnership ${ }^{5}$ (an EU lifelong learning programme) have put together guidelines for ethics in digital storytelling, this is an area that is currently under-researched, specifically in HE. Some universities internationally, like the University of Wollongong ${ }^{6}$ (Australia), the University of Toronto ${ }^{7}$ (Canada) and the University of Brighton ${ }^{8}$ (United Kingdom) have placed caveats on their websites regarding ethical behaviour in digital storytelling. There is not much evidence, however, that other universities are actively seeking to publish specific guidelines in this arena. A recently published anthology on DST in higher education features only one chapter on the ethics of DST in HE, although some chapters do refer to ethical challenges when introducing DST into teaching, research or community engagement (Jamissen, Hardy, Nordkvelle \& Pleasants, 2017).

\section{HE institutions engagement with the ethics of digital storytelling}

The StoryCenter, ${ }^{9}$ under the leadership of Joe Lambert, is dedicated to the telling and collecting of stories and propagates the use of DST in particular. This organisation has been instrumental in rethinking the generalised ethics that have been transferred from the realm of historical oral storytelling and participatory media production, in order to create guidelines for DST. The change of name from the Center for Digital Storytelling to StoryCenter also indicates a heightened awareness of the sensitivity of engaging with personal stories and aims to be more inclusive and ethical in its dealings with participants. The

3

4

5

6

7

8

9

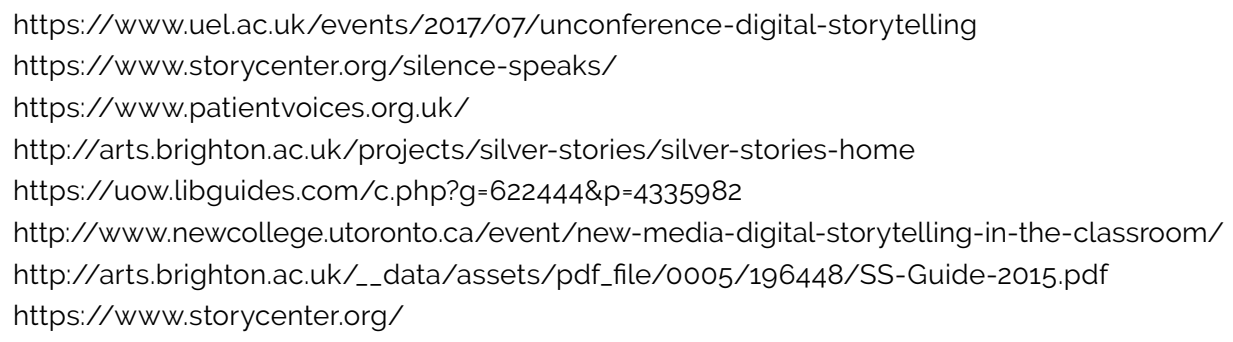


StoryCenter places the wellbeing of the storyteller at the heart of its ethical processes and stresses the importance of ongoing consent (StoryCenter, 2018). One of the unique ethical issues, related to storytelling, that is addressed by the StoryCenter relates to the issues of ethical knowledge production and ownership and the concerns related to the ethical dissemination of digital stories ${ }^{10}$. This is of particular interest to the DST arena, as the idea of "digital afterlife" (Ban \& Nagy, 2016:57) may raise moral and ethical questions as to whether or not a researcher may or may not use 'the other's' story, in an ongoing research cycle, so organisations often negotiate 'right of use agreements' rather than copyright agreements (Concordia University, 2018). A further ethical aspect that is highlighted by the StoryCenter is that of cultural sensitivity and the need for contextual awareness, not only in the recruitment of storytellers, but in the manner in which they are treated. An additional stress is placed on the fact that ethical engagement is an ongoing process and cannot be seen as a 'once-off' phenomena of gaining consent. ${ }^{11}$

An arena which has seen a flood of work related to situated ethical practice is that of the public health sector, particularly in relation to DST. This is highlighted by the work of Gubrium, Hill and Flicker (2014: 1606) who conducted a metaanalysis of several DST projects in public health and highlight what they call "moments of ethical debate and tension" specific to the public health sector, which were encapsulated in the ethical conundrums of fuzzy boundaries, recruitment and consent to participate, power of shaping, representation and harm, confidentiality and release of materials; issues which have also been identified by the StoryCenter. Amy Hill (2014), also working in the public health sector, slightly amended the StoryCenter's bill of rights to reflect the even more sensitive context in which she and her organisation, Silence Speaks, operates. ${ }^{12}$

With DST being embraced across HE, institutional committees, mostly from the US, UK and Australia, have been formed to draw up guidelines on an ethical practice of DST. However, from our literature review, we have learned that these ethical guidelines often draw from two specific disciplines, i.e. oral history or photography, tend to engage only certain ethical aspects of DST and are not as holistically concerned about the wellbeing of the storyteller, as for example the StoryCenter.

$10 \mathrm{https} / / /$ static1.squarespace.com/static/55368c08e4bod419e1c011f7/t/579134a05016e13d de264720/1469133984611/Ethics.pdf

11 For a full list of principles of an ethical DST practice and the storytellers' bill of rights see https://static1.squarespace.com/static/55368c08e4bod419e1c011f7/t/

579134a05016e13dde264720/1469133984611/Ethics.pdf

12 https://WwW.storycenter.org/silence-speaks/ 
Universities like Concordia University and the University of Cambridge ${ }^{13}$ and organisations like the Oral History Society ${ }^{14}$ that collect oral histories have long known about the ethical dilemmas and dangers inherent in collecting personal stories, and were the first to put situated ethical practices in place. The predominant ethical guidelines related to storytelling, in both the oral and digital forms, have grown from the lessons learned in history departments at universities. Concordia University (2018:n.p.), for one, acknowledges that ethics lie at the "heart of oral history theory". At the heart of ethical behaviour in collecting oral histories is informed consent, mitigation of harm and the right to withdrawal (Concordia University, 2018). Specific interviewer behaviours, such as dealing with cultural sensitivities and responding to emotional reactions by storytellers, have also been targeted for ethical discussions.

DST has diverged from oral histories' concerns around ethical issues regarding the images used in digital stories. Universities concerned with these issues follow the guidelines of organisations such as the National Press Photographers Association ${ }^{15}$ around the ethical use and taking of photographs. Images are powerful, and part of the ethical practice needed in DST is to acknowledge that visuals are not 'neutral', and inherent power dynamics between the 'photographer' and the 'photographed' need to be addressed. It is also important that ethical behaviour is adhered to with regards to the use of downloaded images from the internet. Prager (2017) has compiled a guide to navigating the sensitive arena of copyright with regard to the use of internet images. These guidelines include explanations of copyright and fair use and outline when you can use an image that has been downloaded from the internet. There are also suggestions on how to create your own images and how to use free images.

Other unique aspects in the genre of DST that make an additional engagement with ethical processes necessary, concern the sharing of digital stories online and the potential trauma that DST can cause. With the introduction of participatory storytelling projects and the online dissemination of stories on platforms like YouTube, the situated practice of ethical DST has to be modified to fit the demands of these forums. The generalised ideas of consent, harm and the right of withdrawal have remained as pillars of good ethical practice, but issues regarding the dissemination of stories, copyright and the potential risk for participants are concerns that have come to the fore and need to be properly

13 https://www.hist.cam.ac.uk/graduate-students/phd-years-2-4-handbook/oral-historyguidelines

14 http://www.ohs.org.uk/journal/

15 https://nppa.org/code-ethics 
addressed. The following section discusses some of the assumptions on which the StoryCenter DST model is based, and this center's guidelines of ethical practice, which are not necessarily applicable to a HE context. Furthermore, we will address gaps we recognise in the current guidelines for ethical practice in HE. This section is split into three parts (1. teaching and learning; 2 . research; and 3. community engagement), and each part is preceded by an example of an ethical dilemma from our own practice - although some of the issues highlighted cut across all three areas of practice.

\section{General assumptions about DST and how practices differ in $\mathrm{HE}$}

\subsection{DST in teaching and learning in $H E$}

Snapshot 1 (Daniela): I sit in a story circle with five students. We have heard a number of painful stories. Students have opened up, surprising me with their honesty and willingness to share. There were tears; we had to stop at various points to allow students to compose themselves. Students have hugged, shared tissues and listened intently. So far, the group has managed to support each other, to contain the pain. The last student is a young white woman. Her story stays on the surface. I try and push her, ask probing questions, trying to help her dig deeper. Still she resists. Suddenly she bursts out in tears and leaves the classroom. I don't know where she has gone. She doesn't come back to any of the workshops. Through the grapevine I hear that she has complained to the department head, arguing that such personal projects shouldn't be part of the curriculum. I worry about her. What if she cannot complete the assignment? What if she won't be able to finish the course because of this project? For the rest of the project I feel vulnerable and uncomfortable. I don't see her again until the day of the final screening where she shows a beautiful movie she did on her own, with the help of one of her peers. A huge wave of relief overcomes me.

With consideration of the literature on ethics in DST in teaching and learning: there are a number of assumptions these frameworks/principles and guiding questions are based upon which have no resonance in our context (as illustrated in the 'snapshot' above). Some of the most important examples of these are:

Assumption of small group and workshop context: Digital storytelling originated from a community space. Traditionally, the DST format, as promoted by the StoryCenter, includes a 3 - 5 day workshop in which a small group of participants is supported in developing digital stories, being carefully guided in sharing their 
story ideas, developing a script, recording a voice over, selecting images, using video editing software to assemble all these elements into a short video and finally watching the movies together. In HE, while we do run small group workshops for staff and students, DST projects realistically will be set for a whole class comprising anything from 30 to 200 students. This means adapting the workshop format in all sorts of ways, from weekly sessions over a period of several weeks (up to 10 weeks in some instances) (see for example Hardy (2017); Condy et al., (2012); or Livingston (2014)) to self-directed processes (either independent or group-based). While lecturers are creative in adapting this method to support these often large classes (from training peer facilitators to support smaller groups of students to creating digital stories in groups), this means that the level of support will be compromised in this context.

Assumption of voluntary participation/consent/right to withdraw: Traditionally, consent has been a big concern in DST. The right to consent and withdraw are essential elements of the DST process. How does that translate into the HE space where participation in DST is in general compulsory, as it is part of the curriculum and more often than not will need some form of assessment? What does that mean for students who don't feel comfortable or simply cannot or do not want to participate and share their stories, as in the story above? Is it enough to allow students to choose the story they want to share and to be as personal or impersonal as they feel comfortable with? What if there are religious reasons for students not to participate? Or medical, i.e. if students have experienced trauma and the process of DST triggers it? Can they be forced to engage in this process? Amy Hill in her 2010 chapter, for example, suggests that DST should not be used with participants who suffer from PTSD.

Assignment briefs and a careful selection of the model stories shown to students as examples of the genre will go a long way in framing stories and having an impact on the level of personal sharing students will feel able/ prompted/required to do. However, anybody who has ever taken part in a story circle will be able to attest at the 'magic' of these storycircles, the core of the DST process, unearthing stories that participants would have never thought to share in the first place. Can/should these stories be limited? What would be a cause of concern for facilitators? Stories that could potentially incriminate students or trigger other students? Open wounds we are not able to heal?

What about assessment? How closely does a student have to address a brief? How much choice is there in terms of style, language, content and creativity? And how can these very personal stories be assessed? Who should assess 
them? Should they be assessed at all? Attempts at assessing digital stories are often done through rubrics loosely following the Seven Elements of Digital Storytelling ${ }^{16}$, sometimes in conjunction with a reflective essay (Benmayor, 2008; Hardy, 2017; Condy et al., 2012). Other examples include drawing up a series of milestones students have to complete (Livingston, 2014; Stewart \& Ivala, 2017) or selfand peer-assessment. Still, as Hessler and Lambert argue, these attempts "usually lead one to learn just as much about who is doing the assessment, and what they are signifying about themselves or their institutional context" (2017:28). Hill (2010) argues that the collective of stories developed in a DST process can create a collective social story of injustice or struggle, which helps to move beyond the individual trauma of a story. As such, assessment should always bear in mind that the ultimate goal of DST is to help participants become more "empathetic, attentive, and collaborative learners" (ibid:32).

Space, skills, technology: Because DST is often done in facilitated workshop settings, access to technology and the skills to use this technology are required. Facilitators should have access to a workshop space conducive to the sharing of intimate stories and a set range of technology for all participants to ensure that they acquire skills to create and share digital stories. This would offer a level playing field in terms of output. Often facilitators take over a post-production phase to guarantee a high-level outcome that can be screened or shared with a wider audience, in particular if stories were shared/produced for advocacy purposes. In HE (in particular in resource-restrained contexts such as ours) none of this is a given. Spaces are often non-conducive to group storytelling (story circles). Classrooms might have furniture that cannot be moved around, no privacy can be given or groups of students might have to tell their stories in a crowded, noisy room, sometimes even in corridors or other shared public spaces. Students most likely will have to source their own technology/equipment, leading to highly varied outputs and quality of stories. Storytelling and multimodal/digital skills will also vary among students. Lecturers might not be able to support all students in equal ways (might not even have all the skills themselves). Even though there are creative ways to engage with this (such as co-teaching with colleagues/ student assistants across courses with diverse skills sets or sourcing labs/technology across departments and faculties), the quality of output will differ and will have an impact on how an audience reacts to shared stories. As Hessler and Lambert argue "[c]reating environments where all of those differences and

16 http://www.ucdenver.edu/faculty_staff/faculty/center-for-faculty-development/

Documents/Tutorials/Rubrics/documents/ex_digital_storytelling.pdf 
capabilities are appreciated, but where none are overly privileged, becomes the distinct challenge for the educator" (2017:32). This leads to the next point around support and facilitation of DST projects.

Support/skilled facilitators: Traditionally, DST facilitators will undergo rigorous training. The StoryCenter offers an intensive programme for facilitators, often spanning years of (costly) training. This is one of the reasons why DST is seen as an exclusive, hard to access practice. But it must be noted that this intensive training is what encourages the appropriate emotional support for participants, who often share difficult stories or trauma (see also next point around expectations of catharsis). In HE, lecturers often adopt DST with little exposure to good practices of DST or enough training in DST facilitation. In the best case scenario, they might have participated in a workshop themselves and created their own digital story. In many cases they might just have heard about DST at a conference or read an article about this practice.

Novice facilitators to DST struggle to understand or foresee the unintended consequences of it, which is the opening up of spaces for the sharing of personal stories that cannot be closed again. How to support students making themselves vulnerable, how to create a space that is as safe as possible, how to care for the stories told and the audience response, what to do once stories have been shared and needs for care have been expressed - these questions all remain unanswered. Where does the responsibility for a storyteller, a story and the audience end? What do we do with the stories shared? Is it enough to refer an emotionally unsettled storyteller to student counselling? The story was shared in a particular space, to a particular group of people - the trust given calls for a level of responsibility that cannot be responded to by a referral to external psychologists or counsellors. What if students are not comfortable accessing counselling services based on their cultural beliefs and practices (in African culture 'therapy' is still very much seen as a Western tradition not necessarily in line with local customs and practices to engage with emotional fallouts)? Also, while traditional workshops have a demarcated timeline and, in some ways, a clearly defined window of responsibility for the facilitator, for a lecturer running a DST project, the responsibility for students does not end with the end of the project but will continue for as long as he/she teaches the students participating in the DST project. How should I have responded to the student leaving the story circle in the snapshot preceding this section? 
Assumption of story as therapy/healing/catharsis/transformation: Closely related to the above-mentioned point is the assumption that DST, or rather telling stories in general, is cathartic, healing and that they are seen as therapy. Often DST workshops are centred on difficult topics, marginalised groups (such as women suffering from gender-based violence), survivors of war trauma or patients with specific medical conditions. However, when DST is adopted in HE, the focus must move from a therapy intervention to a pedagogical space. The most consistent feedback we get from students is the importance of these kinds of projects for their own personal growth, a space that is usually not created in the often rigid $\mathrm{HE}$ context. However, we are first and foremost educators, not counsellors or psychologists. One of the approaches we have taken is to adopt a pedagogy of discomfort (Boler \& Zembylas, 2003), which intentionally moves away from 'psychologising' individual students to an understanding of trauma as a collective, shared, constructed and inherited experience. Digital storytelling can be seen as both a transformative educational experience on an individual and social level (Hessler \& Lambert, 2017), but the boundaries between therapy and education need to be clearly defined and spoken about.

\subsection{DST in research in $H E$}

Snapshot 2: Dilemma in research (Candice): Nadine is a young artist who volunteered to take part in an autobiographical DST project as part of her fourth-year final exhibition. In her digital story, she revealed that she had been sexually abused as a child. Although Nadine gladly signed the consent and release forms, and was quite happy to share her story with the class and the greater research community, I, as both facilitator and researcher of this process, couldn't help but wonder what psychological fallout could have arisen from her disclosure. The fact that I still watch her story, four years later, leaves me wondering if Nadine is OK, as I have never followed up on her wellbeing; not at the time of the writing of the story, or now, many years later. As she has left the school, I wouldn't even know how to contact her.

From its inception, DST has always been a research-based practice, often driven by an educational agenda (Meadows, 2003:189). The general principles that are adhered to in research projects can be transferred to research in DST, but there are a number of assumptions regarding research that are challenged by this practice in a $\mathrm{HE}$ context. These assumptions relate to the collection of data, the anonymising of that data, the manner in which the participants are sampled, the prerequisite confidentiality offered to the participants and their right to give and withdraw consent from an educational research project. The final assumption 
in a research context is that participants will be protected from harmful or risky situations.

Collection and analysis of data: An assumption in research is that data should be collected through a number of validated or reliable instruments. Most research ethics applications require that you provide an example of the instrument that you will be using to collect your data. But is it possible to validate or ensure that the data - in form of a digital story - is reliable, as it is by nature subjective, deeply personal and emotional? It is true that DST often provides a rich source of data for the understanding of and engagement by a diverse student body, but the niggling question at this point is: How can intensely personal stories be ethically viewed as data and how can this be collected ethically without the storyteller becoming a mere participant and the story becoming a mere artefact? When does the data from personal stories move from a personal sharing of stories space into the scholarship of teaching and learning? And is it ethical to represent and write about this data in a traditional way? At the least the researcher should state his/her positionality upfront to allow readers to understand how he/she is reading the stories collected. Also, participant checks will help ensure that storytellers are represented meaningfully and ethically (see more on representation in the community engagement section).

Anonymity and confidentiality: There is also an assumption in research that participants in a research project will be granted anonymity and that the data produced in the research context will remain confidential. Due to the nature of DST and the public dissemination of the stories, this is next to impossible. This is probably the greatest concern within the HE research contexts: Students might feel safe when sharing their stories in a story circle and may also give consent to share their story during a class screening, but what happens if their stories are shown at a conference where anonymity and confidentiality cannot be guaranteed? And how will they feel when they finally read the academic publication that resulted from a research project? How much confidentiality can thus be ensured, especially - as we will later argue - since the storyteller should be invited into the conference space, if possible to introduce her/his story?

Sampling and consent: An important assumption in qualitative research is that sampling is purposive but also voluntary. As shown in the example above, Nadine's digital story was part of her final year art portfolio, and although she had a choice whether or not she wanted to share her story with the greater community, she 
had no choice about the completion of her assignment. This then raises the issue of whether it is ethical to include a research component in an academic DST project, when students are forced to take part - especially if their participation in the project is not voluntary and forms part of an assessment. Lecturers may give the student the option to not have his/her story used as data in a research project, but their participation in the project is still mandatory. This leads to the questioning of power dynamics between the storyteller and the researcher (who is very often the lecturer). If a student does not have a say over whether or not they want to take part in a digital story project, how can this sampling strategy be seen as valid, especially if the student feels coerced into taking part in the project and feels as though they have lost their 'voice'? This feeds into the contentious issue of consent. How can a lecturer ask a student to give their consent to be in a project and use their artefacts when, in essence, the student has no consent to give particularly as the project is compulsory? How much choice does a student have to not participate in a study if the researcher is their lecturer, most likely the person assessing their work as well?

Because of the highly constrained format of DST (length, topic), stories have to focus on the mere essentials and often do not provide a lot of background information on the storyteller. When a story travels beyond the classroom or institution and is shared at a conference - far removed from the context where it was produced in - who will provide context? Can the researcher be relied on to provide the necessary backstory? Should Nadine be invited to co-present, co-write with me (the researcher in this case) as participatory research would suggest? And how will the story be introduced and 'read' by a conference audience? Hill (2010:138) asks for "resisting simplistic and passive readings in favour of readings that encourage viewers to reveal their own stories and open themselves to raw vulnerability (comparable to that exercised by the storytellers in sharing their lives in the first place) and a form of emotional distress or confusion which makes simplistic explanations or solutions impossible." How can this be realised in a traditional conference setting where time for presentations and questions and answers is often limited to 20 - 30 minutes?

In Nadine's case, consent was a once-off action and was never revisited. With a story of this nature, with its sensitive content and deeply personal revelations, should consent not be sought every time the story is shown, even if it is years later? What if Nadine changes her mind about her story? Layered consent is something that must be considered. What would ongoing/layered/continuous consent look like in this situation? Will this be possible if the research has been published? It would be ethically responsible to withdraw a conference presentation 
or an article from publication if the student changes the conditions of their consent at a later stage, but how viable is this really?

Do no harm: The final assumption regarding research is that a participant will not knowingly be put in a situation which could harm them or expose them to unnecessary risk and that the reputation of the HEl must be safeguarded. It is also known that an institution may be subject to vicarious liability if they knowingly put a student in harm's way or do not take the necessary precautions to protect a student from harm or risky situations. But, as shown in the dilemma above, is it possible for a facilitator (who is often both the lecturer and researcher) to mitigate the emotional harm that may arise from a disclosure of this nature, especially if the only ethical training that the facilitator has received is quite often perfunctory? Is the facilitator able to deal with the psychological ramifications of this disclosure, both for the student and themselves? As discussed above, is it good enough to only offer the services of the on-campus counsellor? And what about future risks? What if the student has a delayed response to her disclosure, and years later decides that she does not want her story to be told? This raises issues for researchers who should adhere to the ethical principle of 'do no harm'. We have to ask ourselves, are we properly equipped as researchers to, firstly, identify the risk and, secondly, deal with the consequences of the emotional fallout of DST, both at the time of viewing the story, and, later, when the DST process has been completed? The final question that has to be debated though, is: How is it ethically viable for a lecturer to conduct a DST workshop without being able to mitigate this possibility of harm or offer the prerequisite support?

\subsection{DST in community engagement in HE}

Snapshot 3 (Jacqui): My story begins with a Journalism Alumnus who approached our unit requesting logistical support for his project with the District Six (D6) community ${ }^{17}$. The aim of the project was to compile a film of the stories of former and current residents who had been forcibly removed. Our Cape Town campus (recently renamed as D6 campus) was built during Apartheid as the Cape Technikon, serving a predominantly white student population. At first, I delayed responding to the request as I felt that it was critical that we spend some time to engage with the community to understand the project. At the same time there was an expectation to act on the community's request that their stories be digitised. My university also

17 The District Six community is one of the most prominent sites of forced removals as a consequence of the Group Areas Act during Apartheid. For more information visit http://www.districtsix.co.za/ 
needed to display to the community (which included alumni) that we were serious about building connections to honour the history of the space occupied by the D6 campus. I felt stuck in the middle of these expectations, being both a representative of my institution and having myself family history in D6. The screening of the films was followed by an intergenerational dialogue with community members, university staff and students. Photography students developed audio-visual materials (in the form of digital stories) from their interviews with D6 community members. The project highlighted the individual agendas of the key role-players: 1) The need of the community participants to share/tell their stories; 2) The need for the journalist and filmmaker to get stories that would 'sell' and make for good viewing; 3) The need for the university to involve and conscientise students to the history of the D6 campus and to show the building of partnerships between themselves and the D6 community within this highly contested space. The stories generated a wide range of emotions from communities and students, which was expected. What was unforeseen were the political tensions that were revisited and regurgitated between the university and the external community. In retrospect, inadequate attention was given to preparing the students and the community. During the process, there were no strategies put in place to support the participants and no indication was given as to what would happen to the stories post project. One question which has sprung to mind is: How do we as the university practice DST ethically to act in the interests of all parties (staff, students and all partners), especially in highly charged political environments where we have much to lose but also much to gain?

While DST in community engagement can have many forms and can include training community members alongside students, at our institution, DST in community engagement often means students collecting stories within communities and creating digital stories on their own/back at the institution. This can lead to a number of ethical dilemmas as shown below as the usual assumptions in a DST process and community engagement practices clash.

Collaboration, trust and competing agendas: Community engagement (servicelearning and civic engagement) projects, as advocated and practiced by most HEls, are largely dependent on the building of strong partnerships between the university and society. More directly, for staff, students, community and government partners, the presence and practice of trust, empathy, transparency and respect, amongst others, are important components. Boughey (2014:105) echoes the view of Dazé, Ambrose and Ehrhart (2009:21) who describes 'development' as a "creative collaboration around an emergent agenda", based on a foundation 
of "relationships with individuals and communities". Collaboration becomes complicated as students, lecturers, researchers and their collaborators are motivated to engage in community engagement projects for different reasons. Students might be in it for a mark, lecturers because they have been told to and the community due to a need to share their stories. What if they encounter community members that are illiterate and do not fully understand what they are giving consent to/participating in? This might lead to unequal buy-in and a skewed sense of collaboration, where different partners contribute on different levels of emotional engagement. What might be a box-ticking-exercise for some might be deeply personal for others, thereby affecting the relationship of trust that should exist between the parties involved. As shown in the snapshot above, this can be made even more intricate by the presence of a media partner in the partnership. Trust develops overtime and the building of sustainable relationships with communities around DST projects needs to be a concerted effort between the institution and the community (Bickel, Shewbridge, Huebler \& Oskoz, 2017).

Dealing with emotional responses: DST in particular as a community engagement tool may emphasise the digital aspects and film-making process rather than an engagement with the emotional responses encountered. Students may be trained in digital storytelling but not in empathetic interviewing skills. While this is highlighted in oral storytelling ethical practices, it is not given enough credence in current DST community engagement projects. Another aspect to consider is that the storytelling environment can become considerably more emotionally charged when the 'story collector' becomes/is a participant in the process. Often students collect stories in their own community, which can contribute to a sense of connection and collective caring with others. But what if they find out something about their past which is traumatic or experience some sort of cognitive dissonance? Here in the Western Cape, for example, family histories around slave heritage or forced removals are often shameful and silenced and students finding out about these aspects of their family history could present them with emotional difficulties. Another question then is: Who is responsible to respond for this emotional fallout? The lecturer, the student or the community member? All of them?

Equal partnerships: Bringle et al. (2009:3) and also Van Schalkwyk and Erasmus (2011:67) usefully differentiate between a 'relationship', which broadly refers to all types of interactions between persons, and a 'partnership', which refers to a relationship in which the interaction possesses the three qualities of closeness, 
equity and integrity. These qualities may be pertinent to consider when building an environment for engagement with communities. Closeness is a function of three components: (a) frequency of interaction, (b) diversity of activities that are the basis of the interactions, and (c) strength of influence on the other person's behaviour, decisions, plans and goals. The quality of equity is not measured by the comparison between what was invested in the project and the end result, but by the degree to which the end results are perceived as being proportionate to the initial inputs. These relationships have high levels of integrity, share deeply held internally coherent values, and propose a vision of a future transformed world.

One of the core elements in DST is the story circle, where storytellers share their initial stories. In community engagement projects, where students are sent out to collect narratives from community members, this story circle is often left out of the DST process. One might argue that this then does not count as DST, but still many lecturers refer to these projects as DST. What happens then, when certain members of the partnership have more tools/skills/power than others? Who takes decisions regarding production/pictures/the story that will be told? The students? The students in collaboration with community members? The community members? What if students do not have the time for a lengthy postproduction process or consultations? Will the community members ever see the final product/the final digital story? Will they be invited to the screening? Could any costs such as transport costs be covered? Who has the final say in whether the story will be screened? The student or the community member? Could community partners be part of the assessment of the stories? And how could this be encouraged, made possible by the lecturer?

Reciprocity: In service-learning and civic engagement, the principles which influence good practice is when community relationships strive to be mutually beneficial (Clayton, Bringle, Senor, Huq, \& Morrison, 2010). The concept of 'reciprocity' is on occasion utilised by practitioners to indicate this very basic commitment to a partnership that is mutually beneficial through the exchange of resources, but, a deeper and broader interpretation can be related to mutual transformation. According to Jameson et al. (in Clayton et al., 2010:18), this understanding of the term "emphasizes shared voice and power and insists upon collaborative knowledge construction and joint ownership of work processes and products", which then creates an environment where development is inclusive of all participants. As service-learning partnerships require reciprocal partnerships, this concept should be extended to incorporate the 'reciprocity of 
care' as part of the partnership guidelines. In projects where students collect community narratives and produce digital stories, what participants get out of this project may differ. Are students passing on some of their skills to the community? If community members give up their time to be part of storytelling sessions, will they be remunerated? Who owns and benefits from the media products emanating from the project? And will these community members be credited in any academic or digital outputs that are produced by the project?

Dialogue and equal engagement across generations: Community engagement relies on deep dialogue and sensitive engagement with cultural context before, during and after interventions. Students might not be adequately prepared for this type of engagement (as evident in the unforeseen political fallout in the snapshot shown above), but might also not have sufficient time in projects that are often rushed to meet tight deadlines and demands of full curricula. The diverse agendas of the participants and partners may not emerge during the project but becomes evident at a screening when the end product is showcased to a broader audience. Further engagement with this particular community then becomes framed within this paradigm, which can have a negative influence on the relationships between those who are left behind. It is important to acknowledge these agendas upfront and to be open and transparent during the storytelling journey.

Representation: Having a historical bias, a particular political ideology or culture can influence the relationship between the storyteller and story collector, especially in the case of projects like the District Six one which deals with the traumatic legacy of forced removals by the former Apartheid government. When there is a strong political and cultural identification between project partners, the collector (in this case the student) can assume that he/she possesses the legitimacy to access, develop and package the stories into a final product and to own and distribute the story on behalf of the community with which he/she strongly identifies. This then also raises issues of representation of the depicted community and the potential for misrepresentation by either party, for any number of reasons, including for personal or political gain. As mentioned before, will there be time for the student to go back and do a 'participant check' with the storyteller to ensure that there is a fair representation of the community in their digital story? 


\section{Conclusions}

In this chapter we have tried to unpack some of the ethical dilemmas we have encountered in our practice when introducing DST into teaching and learning, research and community engagement. We believe in the process of DST as a means to create a space for sharing and learning about self and other, which is rare in the HE context we operate in. However, to continue promoting this practice, we have seen the need to alert colleagues of the ethical perils they may encounter in this highly personal and powerful practice. In HE we work with many limitations and challenges that the traditional DST do not have to consider, as we have shown above, and, as such, general guidelines on ethics are not fully appropriate.

We are aware that we are asking more questions than providing answers for the moment. While we are working - in parallel to this paper - on guidelines or rather guiding questions for an ethical practice of $\mathrm{DST}$ in $\mathrm{HE}^{18}$, we are hoping that this chapter may encourage educators, researchers and community engagement practitioners to take a step back, reflect on their own practices, consider some of the questions we asked and add their own. Following political philosopher Joan Tronto's 'Ethics of Care' approach, we believe that, at the end of the day, much more important than sticking to guidelines and principles, ethical practices are everyday decisions of care in caring relationships (Tronto, 1993; 2001). It is in our everyday practices of caring for ourselves and others that we most need to consider and practice ethical behaviour (Tronto, 2001). Tronto sees care as a complex ethical relationship in which all participants or actors need to be involved. There can be no one person solely responsible for decision making in a caring relationship or web of relationships such as the DST practice discussed in this chapter: All parties involved should contribute to the discussion on caring needs and how they should be met.

When storytelling enters HE (in and beyond the institution), the educator/ researcher/community practitioner becomes an active participant in this process, learning from and with students/participants through dialogue and mutual respect. When DST moves into the pedagogic sphere and becomes data for research projects in the HE arena, it is essential that we as academics and researchers learn to navigate this terrain, not by consulting a checklist of ethical rules relating to gaining consent and 'doing no harm' and making the prerequisite ticks; rather, we argue, that we need to see DST and the ethics around DST from a situated practice perspective, where consent is a contextual, scaffolded,

18 https://docs.google.com/document/d/1sV6Dn3N_8xCTF_7kTP8p6VmoyDVMuvV4Oz hQ-SghaUA/edit?usp=sharing 
ongoing and layered process and the principles of mitigating risk and harm become embedded in the project before, during and long after the process has been completed (see also Gachago \& Livingston, 2020). There is a need for 'improvisation', for flexibility, rather than rigid rules and regulations in teaching, learning and research practices of this nature (Bliss, 2017), where we as facilitators are challenged to think on our feet - together with students, participants and community members. If the ethics of care is to be embedded in a DST project, we will have to begin with an ethical appraisal of ourselves and our motives and endeavour to ensure that the entire DST process is more than just ethical - it should be ethically sustainable for the dignity of the students, especially with regards to the emotional fallout that these projects might elicit. In essence, the rules of engagement have to be negotiated and agreed upon on a continual basis, not only with regards to issues of scaffolded consent and choice, but also to those of power-sharing, ownership and digital afterlife of the stories as morethan-data.

What that means for us, is that we all - lecturers, students, researchers and community members - need to take responsibility for our DST projects and care for both ourselves and others involved in these projects. Communication, negotiation of rules, active listening and response, and witnessing become important elements in this process. Storytelling then becomes a caring, consensual mutual practice (Bliss 2017) of ethically sharing and listening, responding and acting in and beyond the HE classroom.

\section{Acknowledgements}

We are deeply thankful to the Ethics Deme participants at the 2017 Untold Conference who shaped our thinking around the ethics of digital storytelling and in particular allowed us to recognise the many DST practices with all their different ethical concerns and encouraged us to work towards specific guidelines for HE. We would also like to thank the SA Story Worker Group who helped us think through some of our ethical dilemmas. And finally, thank you to our colleagues and students; without their passion and stories there would be not DST practice at our institution. 


\section{References}

Ban, D. \& Nagy, B. 2016. iDig stories: Digital storytelling in practice. http://idigstories.eu/ wp-content/uploads/2016/og/Digital_Storytelling_in_Practice.pdf, date of access: $18^{\text {th }}$ of August 2020.

Benmayor, R. 2008. Digital storytelling as a signature pedagogy for the new humanities. Arts and Humanities in Higher Education, 7:188-204. https://doi.org/10.1177/1474022208

Bickel, B., Shewbridge, B., Huebler, R. \& Oskoz, A. 2017. Faculty reflections at the intersection of digital storytelling and community engagement. In: G. Jamisson, P. Hardy, Y. Nordkvelle \& H. Pleasants (eds). Digital Storytelling in Higher Education, 371-389. Cham: Palgrave Macmillan. https://doi.org/10.1007/BF03033420

Bliss, E. 2017. Engaged scholarship and engaging communities: Navigating emotion, affect and disability through digital storytelling. In: G. Jamisson, P. Hardy, Y. Nordkvelle \& H. Pleasants (eds). Digital Storytelling in Higher Education, 321-334. Cham: Palgrave Macmillan. https://doi.org/10.1007/BF03033420

Boler, M. \& Zembylas, M. 2003. Discomforting truths: The emotional terrain of understanding difference. In: P. Trifonas (ed). Pedagogies of difference: Rethinking education for social change, 110-136. New York: RoutledgeFalmer.

Boughey, J. 2014. A Comprehensive University at the Heart of its Communities: Establishing a Framework for Engagement. Philosophiae Doctor in Higher Education Studies (Five-article option) in the School of Higher Education Studies Faculty of Education University of the Free State Bloemfontein January 2014.

Bringle R.G., Clayton, P.H. \& Price, M.F. 2009. Partnerships in service learning and civic engagement. Partnerships: A Journal of Service Learning \& Civic Engagement 1(1): 1-20.

Clayton, P.H., Bringle, R.G., Senor, B., Huq. J. \& Morrison, M. 2010. Differentiating and Assessing Relationships in Service-Learning and Civic Engagement: Exploitative, Transactional, or Transformational. Michigan Journal of Community Service Learning. Spring 2010: 5-22.

Condy, J., Chigona, A., Gachago, D. \& Ivala, E. 2012. Preservice students' perceptions and experiences of digital storytelling in diverse classrooms. Turkish Online Journal of Educational Technology (TOJET), 11(3), 278-285.

Concordia University. 2018. Ethics. Centre for oral history and digital storytelling. Retrieved from http://storytelling.concordia.ca/toolbox/ethics 
Dazé, A., Ambrose, K. \& Ehrhart, C. 2009. Climate vulnerability and capacity analysis handbook. Care International. http://www.careclimatechange.org, date of access: $18^{\text {th }}$ of August 2020.

Gachago, D. 2015. Sentimentality and Digital Storytelling: Towards a Post-Conflict Pedagogy in Pre-Service Teacher Education in South Africa. Unpublished PhD Thesis. School of Education: University of Cape Town. https://doi.org/10.13140/ RG.2.1.4738.8403

Gachago, D., Ivala, E., Condy, J. \& Chigona, A. 2013. Journeys across difference: Pre-service teacher education students' perceptions of a pedagogy of discomfort in a digital storytelling project in South Africa. Critical Studies in Teaching and Learning, 1(1), 22-52. https://doi.org/10.14426/cristal.v1i1.4

Gachago, D. \& Livingston, C. 2020. The elephant in the room: Tensions between normative research and an ethics of care for digital storytelling in higher education. Reading and Writing, 11 (1). https://rw.org.za/index.php/rw/article/ view/242/625, date of access: 18th of August 2020

Gachago, D. \& Sykes, P. 2017. Navigating Ethical Boundaries When Adopting Digital Storytelling in Higher Education. In: G. Jamisson, P. Hardy, Y. Nordkvelle \& H. Pleasants (eds). Digital Storytelling in Higher Education, 91-106. Cham: Palgrave Macmillan. https://doi.org/10.1007/BF03033420

Gubrium, A.C., Hill, A.L. \& Flicker, S. 2014. A situated practice of ethics for participatory visual and digital methods in public health research and practice: A focus on digital storytelling. American Journal of Public Health, 104(9):1606-1614. https://doi.org/10.2105/AJPH.2013.301310 https://www.ncbi.nlm.nih.gov/pmc/ articles/PMC4151912/

Haigh, C. 2017. 'The times are a changin': Digital storytelling as a catalyst for an ideological revolution in theal-care research. In: G. Jamissen, P. Hardy, Y. Nordkvelle \& H. Pleasants (eds). Digital Storytelling in Higher Education, 115-130. Cham: Palgrave Macmillan.

Hardy, P. 2017. Physician, know thyself: Using digital storytelling to promote reflection in medical education. In: G. Jamissen, P. Hardy, Y. Nordkvelle \& H. Pleasants (eds). Digital Storytelling in Higher Education, 37-54. Cham: Palgrave Macmillan.

Hessler, B. \& Lambert, J. 2017. Threshold concepts in digital storytelling: Naming what we know about storywork. In: G. Jamissen, P. Hardy, Y. Nordkvelle \& H. Pleasants (eds). Digital Storytelling in Higher Education, 19-36. Cham: Palgrave Macmillan.

Hill, A.L. 2010. Digital storytelling for gender justice: Exploring the challenges and the limits of polyvocality. In: Confronting global gender justice, 126-140. Oxford: Routledge. 
Hill, A. 2014. Digital storytelling and the politics of doing good: Exploring the ethics of bringing personal narratives into public spheres. In: H. Pleasants \& D.E. Salter (eds). Community-based Multiliteracies and Digital Media Projects, 39:174-178.

Peter Lang Publishing.

Jamissen, G., Hardy, P., Nordkvelle, Y. \& Pleasants, H. 2017. Digital storytelling in Higher Education: International perspectives. Cham: Palgrave Macmillan.

Jessee, E. 2011. The Limits of oral history: Ethics and methodology amid highly politicized research settings. The Oral History Review, 38(2):287-307, https://doi.org/10.1093/ohr/ohrog8

Lambert, J. 2013. Digital storytelling: Capturing lives, creating communities (4th edition). New York: Routledge.

Lambert, J. 2017. Foreword. In: G. Jamissen, P. Hardy, Y. Nordkvelle \& H. Pleasants (eds). Digital Storytelling in Higher Education, v-viii. Cham: Palgrave Macmillan.

Livingston, C. 2014. Engaging in art appreciation: A digital autobiographical perspective. In: Fourth international conference on Design, Development and Research (DDR) held in Cape Town on 9-10 September 2014: 107-126. ISBN 978-0-620-62981-0.

Mandal, J., Acharya, S. \& Parija, S.C. 2011. Ethics in human research. Series on ethics in research. Tropical parasitology, 1(1):2-3.

Meadows, D. 2003. Digital storytelling: Research-based practice in New Media. Visual communication, 2:189-193.DOI: 10.1177/1470357203002002004

Prager, D. 2017. A guide to online images copyright and fair use laws. Retrieved from https://www.rivaliq.com/blog/guide-copyright-fair-use-laws-online-images/

Stewart, K.D. \& Ivala, E. 2017. Silence, voice, and "other languages": Digital storytelling as a site for resistance and restoration in a South African higher education classroom.

British Journal of Educational Technology. https://doi.org/10.1111/bjet.12540

StoryCenter. 2018. Ethical practice. https://static1.squarespace.com/ static/55368co8e4bod419e1c011f7/t/579134a05016e13dde264720/1469133984611/ Ethics.pdf, date of access: $18^{\text {th }}$ of August 2020.

Thomson Long, B. \& Hall, T. 2017. From Dewey to digital: Design-based research for deeper reflection through digital storytelling. In: G. Jamissen, P. Hardy, Y. Nordkvelle \& H. Pleasants (eds). Digital Storytelling in Higher Education, 55-72. Cham: Palgrave Macmillan.

Tronto, J. 1993. Moral boundaries: A political argument for an ethic of care. New York: Routledge.

Tronto, J. 2001. An ethic of care. In: M.B. Holstein \& P.B. Mitzen (eds). Ethics in Community-Based Elder Care, 60-68. New York: Springer. 
Van Luyn, A. 2011. An obsession with storytelling: Conducting oral history interviews for creative writing. Ejournalist, 11(1).

Van Schalkwyk, F. \& Erasmus, M. 2011. Community participation in higher education service learning, Acta Academica, 43(3). Sun Media: Bloemfontein. 